\title{
RANCANG BANGUN ANTENNA WAJANBOLIC DENGAN DIAMETER 46 CENTIMETER PADA FREKUENSI 1900 MHz UNTUK MEMPERKUAT PENERIMAAN SINYAL WCDMA
}

\author{
Ichsyan Nafik, Yuniarto \\ Program Studi Diploma III Teknik Elektro \\ Fakultas Teknik, Universitas Diponegoro Semarang
}

\begin{abstract}
Ichsyan Nafik, Yuniarto, in paper a $1900 \mathrm{MHz}, 46 \mathrm{~cm}$ wajanbolic antenna design to strengthen wcdma signal reception explain that the antenna is a device used to transmit or receive electromagnetic waves electromagnetic waves. Reception using an antenna will amplify the signal acquisition in accordance with the ability of the antenna itself. Signal instability that often occurs in WCDMA networks makes the need for strengthening the acquisition of the signal is very large. Antenna Wajanbolic is one option reinforcement signal acquisition. In WCDMA networks, downlink frequency used at $2100 \mathrm{MHz}$, while the uplink frequency to $1900 \mathrm{MHz}$. Antenna wajanbolic Must ditune to resonate in the uplink frequency is $1900 \mathrm{MHz}$. The final project focuses on making wajanbolic antenna for Line of Sight (LoS) who works at a frequency of $1900 \mathrm{MHz}$ for WCDMA (3G). In accordance with the name wajanbolic antenna, this antenna uses a reflector from the pan, with a waveguide of modified pipes are coated with aluminum duct tape, and a signal receiver using a USB 3G modem. From the results of the testing and analysis of the results showed that wajanbolic antenna is directional antenna that has the directivity signal. This wajanbolic got an antenna gain of $16 \mathrm{~dB}$ value.
\end{abstract}

Keyword: wajanbolic antenna, WCDMA, Line of Sight (LOS)

\section{PENDAHULUAN \\ Latar Belakang}

Jaringan mobile sebagian besar telah memenuhi standar koneksi dengan teknologi 3G, Next G atau HSDPA yang semakin mempermudah pengguna untuk mendapatkan layanan internet berkecepatan tinggi. Namun sayangnya, akses internet yang cepat sepertinya susah didapatkan karena adanya ketidakstabilan sinyal pada jaringan $3 \mathrm{G}$ ini, apalagi di lokasi yang kurang menguntungkan.

Salah satu solusi yang mungkin akan dapat menolong menaikkan sinyal 3G adalah menggunakan antenna wajanbolic seperti yang dilakukan pada pengguna WiFi di 2.4GHz.

\section{Tujuan}

Tujuan dari proyek ini adalah membuat antenna wajanbolic yang bekerja pada frekuensi $1900 \mathrm{MHz}$ dengan menggunakanmedia wajan sebagai reflektor. Dengan menggunakan antenna wajanbolic bisa didapat gain antenna yang lebih besar bila dibandingkan dengan modem USB 3G standar.

\section{Batasan Masalah}

Pada proyek akhir ini akan dibuat antena wajanbolic 3G yang bekerja pada frekuensi 1900 MHz. Batasan masalah pada proyek akhir ini antara lain:

- Merancang antena wajanbolic yang mempunyai performa peningkatan gain yang optimal serta tidak kalah dibandingkan dengan antenna built up.
- Perancangan antenna dikhususkan pada frequensi $1900 \mathrm{MHz}$.

- Proses pengerjaan antenna wajanbolic yang diuraikan dengan mudah dan jelas.

- Perbandingan performansi antara gain modem USB $3 G$ tanpa menggunakan antena wajanbolic dengan modem USB $3 G$ yang menggunakan antena wajanbolic.

- Penerima sinyal menggunakan modem USB $3 G$.

\section{LANDASAN TEORI \\ Pengertian antena}

Antena adalah suatu sebuah komponen yang dirancang untuk memancarkan dan menerima gelombang radio atau elektromagnetik.Antena directional merupakan antena yang memancarkan daya ke arah tertentu.

\section{Waveguide}

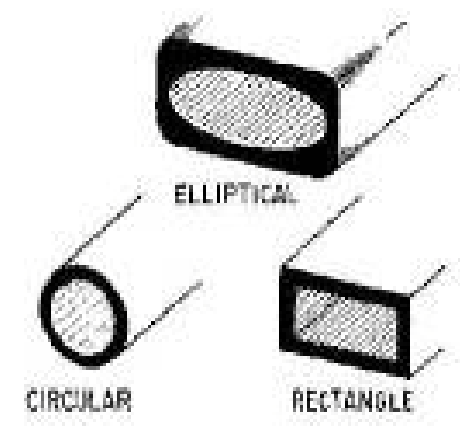

Gambar 1. Jenis Waveguide 
Waveguide adalah saluran tunggal yang berfungsi untuk menghantarkan gelombang elektromagnetik (microwave) dengan frekuensi 300 $\mathrm{MHz}-300 \mathrm{GHz}$.

Waveguide merupakan konduktor logam (biasanya terbuat dari brass atau aluminium) yang berongga didalamnya, yang pada umumnya mempunyai penampang berbentuk persegi (rectanguler waveguide) atau lingkaran (circular waveguide).

\section{Waveguide Silinder}

Distribusi medan untuk mode-mode dari waveguide lingkaran ditunjukkan oleh Gambar 2, Mode $\mathrm{TE}_{11}$ adalah mode yang paling sederhana yang mungkin dapat terjadi pada mode TE untuk waveguide silinder.

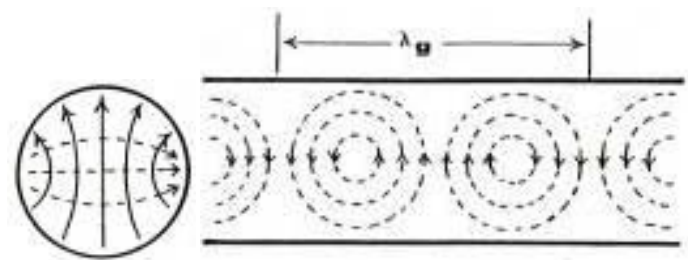

Gambar 2. Distribusi medan untuk TE mode

\section{Coupling Untuk Waveguide}

Untuk membangkitkan suatu mode dari suatu waveguide, diperlukan peralatan untuk menghubungkan energi dari suatu saluran transmisi ke waveguide atau sebaliknya dengan cara memasukkan probe ke dalam waveguide sedemikian rupa sehingga probe muncul di dalam waveguide dengan jarak $\lambda \mathrm{G} / 4$

\section{probe ke kabel USB \\ active extender}

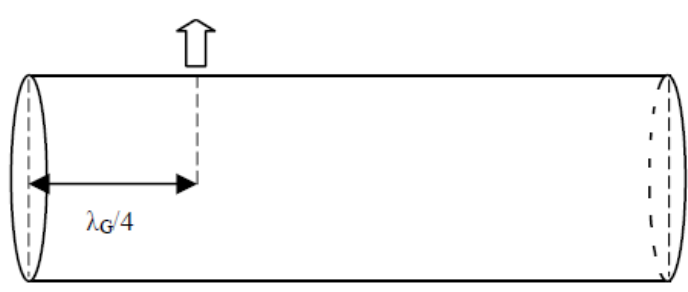

Gambar 3. Coupling untuk waveguide

Gain

Gain antena berhubungan erat dengan directivity dan faktor efisiensi. Namun dalam praktiknya sangat jarang gain suatu antena dihitung berdasarkan directivity dan efisiensi yang dimilikinya, karena untuk mendapatkan directivity suatu antena bukanlah suatu yang mudah, sehingga pada umumnya gain maksimum suatu antena dihitung dengan caramembandingkannya dengan antena lain yang dianggap sebagai antena standar (dengan metode pengukuran). Daya terima antenna berbanding lurus dengan gain, atau dengan perhitungan algoritma

$$
P[d B m]=G[d B]+K
$$

Di mana:

$$
\begin{aligned}
& \mathrm{P}=\text { Power signal yang diketahui } \\
& \mathrm{G}=\text { Gain } \\
& \mathrm{K}=\text { Power signal yang akan diukur }
\end{aligned}
$$

\section{Line of Sight (LoS)}

Pada komunikasi radio di frekuensi sangat tinggi, kondisi LoS antara pemancar dan penerima sangat penting. Ada dua jenis $L o S$, yaitu:

- Optical Line of Sight, kedua stasiun harus dapat melihat satu sama lain

- Radio Line of Sight, tidak boleh ada refleksi, refleksi dan difraksi dari sinyal radio

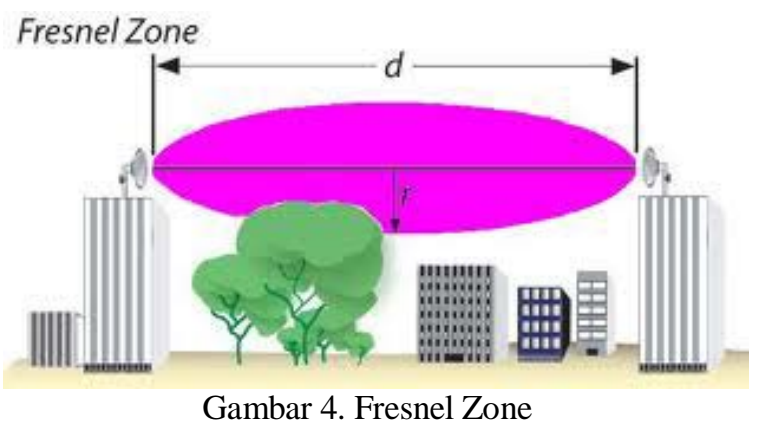

Dalam daerah Fresnel Zone tidak boleh ada pengganggu sinyal. Kita biasanya menggunakan konsensus bahwa 80\% dari Fresnel Zone harus tidak ada halangan yang mengganggu sinyal. Kalkulasi radius dari Fresnel Zone yaitu:

$$
r=43,3 * \sqrt{\frac{d}{4 f}}
$$

Di mana:

$\mathrm{r}$ = radius dari Fresnel Zone dalam feet ( 1 feet $=0,3048 \mathrm{~m}$ )

$\mathrm{d}=$ jarak antara dua titik dalam Miles (1 Miles $=1,609 \mathrm{Km})$

$\mathrm{f} \quad=$ adalah frequensi dalam $\mathrm{GHz}$

\section{Antena Wajanbolic}

Pengertian Antena Wajanbolic

Dalam matematika, parabola adalah irisan kerucut yang berbentuk kurva yang dihasilkan oleh perpotongan menyilang yang sejajar terhadap permukaan kerucut.

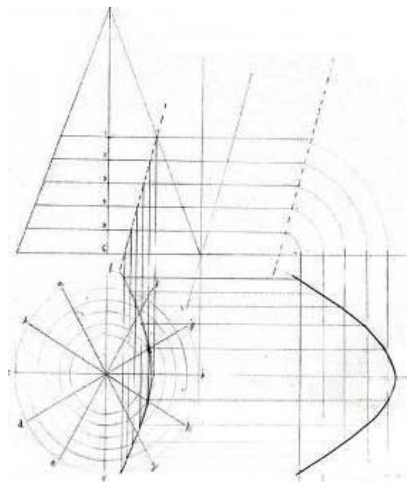

Gambar 5.Irisan pada kerucut sehingga membentuk parabola 
Direktris adalah garis sumbu simetri pada parabola terhadap titik fokus. Sedangkan fokus dari parabola adalah letak suatu titik dimana jarak antara titik sembarang pada garis parabola $M(x, y)$ ke fokus adalah sama dengan jarak antara $\mathrm{M}(\mathrm{x}, \mathrm{y})$ ke direktris $\mathrm{D}(\mathrm{x}, 0)$

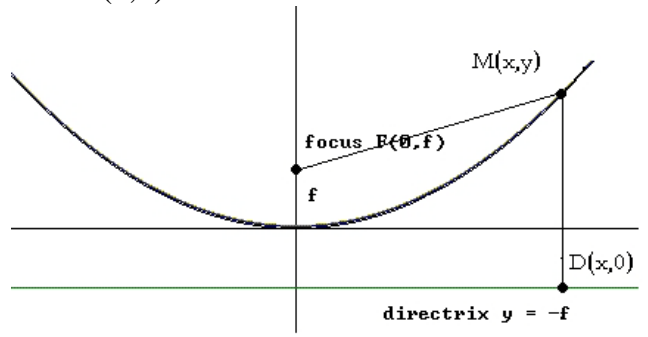

Gambar 6. Fokus dan direktris

Dari pengertian diatas diketahui bahwa nilai dari jarak titik F (fokus) ke titik M dan jarak dari titik M ke titik D (direktris) adalah samam sehingga dapat dihasilkan persamaan:

$$
\begin{aligned}
& \sqrt{(x-0)^{2}+(y-f)^{2}} \\
& =\sqrt{(x-x)^{2}+(y-(-f))^{2}}
\end{aligned}
$$

Karena pada persamaan di atas kedua sisi sama-sama mempunyai akar, maka bias dieliminasi sehingga menghasilkan persamaan:

$$
\begin{gathered}
x^{2}+y^{2}+f^{2}-2 y f=y^{2}+f^{2}+2 y f \\
x^{2}+y^{2}-y^{2}+f^{2}-f^{2}=2 y f+2 y f \\
x^{2}=4 y f \\
y=\frac{x^{2}}{4 f} \\
y=\frac{x^{2}}{4 f}
\end{gathered}
$$

Sekarang perhatikan gambar 7. dibawah, dimana diketahui diameter dari parabola (D) dan kedalaman parabola (d).Dari dua parameter tersebut maka bisa dihitung nilai/letak dari titik fokus parabola.

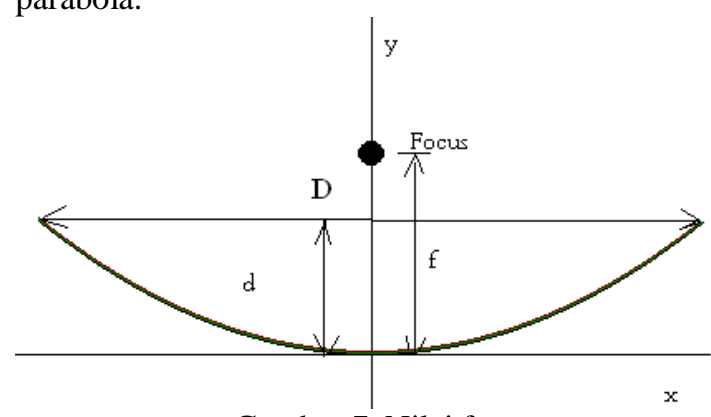

Gambar 7. Nilai focus

Dari Gambar 7., diketahui titik (D/2,d) dan titik (-D/2,d) terletak pada parabola, sehingga:

$$
\begin{gathered}
y=\frac{x^{2}}{4 f} \\
d=\frac{\left(\frac{D}{2}\right)^{2}}{4 f} \\
d=\frac{D^{2}}{4} x \frac{1}{4 f}
\end{gathered}
$$

$$
d=\frac{D^{2}}{16}
$$

Dari persamaan di atas bisa kita ubah menjadi sebuah persamaan untuk menghitung nilai fokus.

$$
\begin{gathered}
d=\frac{D^{2}}{16 f} \\
16 f=\frac{D^{2}}{d} \\
f=\frac{\frac{D^{2}}{d}}{\frac{16}{1}} \\
f=\frac{D^{2}}{d} x \frac{1}{16} \\
f=\frac{D^{2}}{16 d}
\end{gathered}
$$

Dari persamaan diatas bisa kita perhatikan bahwa semakin besar nilai diameter dari suatu parabola (D) dan semakin kecil nilai kedalaman (d) suatu parabola, maka nilai fokusnya akanmenjadi semakin besar.

Dianggap bahwa antena parabola sebagai circular aperture, maka persamaan untuk mengetahui nilai pendekatan gain maksimum adalah:

Dimana:

$$
G \approx \frac{\left(\pi^{2} D^{2}\right)}{\lambda^{2}}
$$

$\mathrm{G}=$ penguatan (gain) isotropic

$\mathrm{D}$ = diameter reflektor dengan satuan yang sama dengan panjang gelombang

$\lambda=$ panjang gelombang

\section{Reflektor}

Antena wajanbolic ini menggunakan reflektor dari wajan yang berbahan alumunium. Dipilih bahan alumunium karena bahan alumunium secara umum merupakan bahan yang ringan bila dibandingan dengan bahan logam lainnya.

Penggunaan reflector ini dimaksudkan untuk mendapatkan penguatan (gain) yang lebih besar biladibandingkan hanya menggunakan wireless USB adapter biasa atau hanya menggunakan antena kaleng (waveguide). Karena setiap gelombang yang datang dari fokus akan dipantulkan oleh permukaan reflektor dengan arah yang sejajar dengan sumbu atau sebaliknya. Sifat reflektor yang baik adalah:

- Setiap gelombang yang datang dari fokus dipantulkan oleh permukaan sejajar dengan sumbu dan sebaliknya.

- Gelombang dari fokus yang dipantulkan oleh permukaan reflektor akan memotong suatu bidang yang tegak lurus terhadap sumbu dengan fase yang sama.

\section{Modem USB $3 G$}

Modem USB 3G berada di dalam waveguide yang ada di depan titik focus dari wajan. Radiasi dari modem USB 3G akan merambat di dalam 
waveguide, kemudian akan diradiasikan ulang oleh reflector.

\section{Antenna WCDMA (3G)}

Antena WCDMA (3G) memiliki range frekuensi berkisar antara 1710-2200 MHz. Tinggi antenanya bervariasi antara $0.5 \mathrm{~m}$ hingga $2.5 \mathrm{~m}$, dengan berat $2 \mathrm{~kg}$ hingga $20 \mathrm{~kg}$. Power yang diperlukan untuk satu antena sekitar 300 Watt dengan penguatan (gain) berkisar antara $15 \mathrm{dBi}-21$ dBi. Umumnya impedansi antena adalah $\mathbf{5} \boldsymbol{\Omega}$ dan memiliki dua input, yaitu Tx dan Rx. Namun untuk antena jenis tertertentu inputnya bisa lebih dari dua.

\section{Spektrum Frekuensi WCDMA}

Rentang pita frekuensi $1920 \mathrm{MHz}$ sampai $1970 \mathrm{MHz}$ yang berpasangan dengan pita frekuensi $2110 \mathrm{MHz}$ sampai $2160 \mathrm{MHz}$ merupakan pita frekuensi yang digunakan untuk jenis seluler dengan UMTS (WCDMA).

\section{PEMBUATAN ANTENA WAJANBOLIC}

Dalam merancang antenna wajanbolic, kita harus mengetahui frekuensi yang digunakan untuk operasi 3G.Antenna wajanbolic 3G harus ditune untuk dapat beresonansi di frekuensi uplink yaitu $1.950 \mathrm{MHz}$.

\section{Perhitungan}

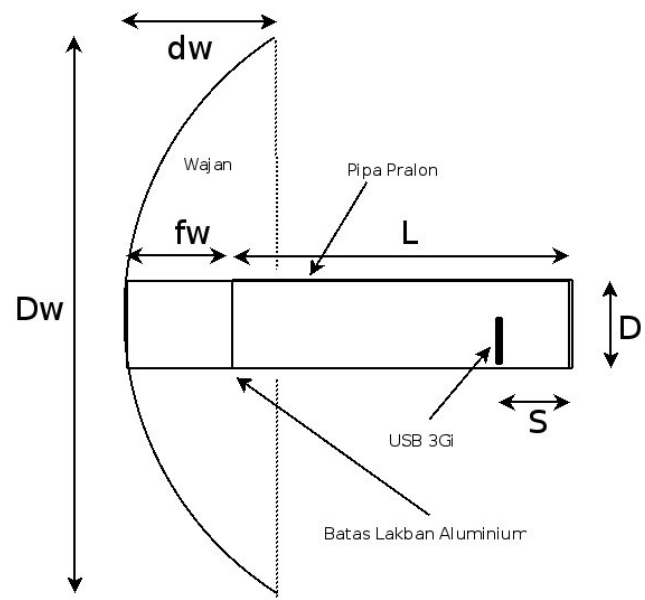

Gambar 8. Bagan perhitungan antena wajanbolic

Pada gambar diatas diperlihatkan sebuah bagan antena wajanbolic. Beberapa parameter yang digunakan adalah :
$\mathrm{Dw}=$ diameter wajan
$\mathrm{dw}=$ kedalaman wajan
$\mathrm{D}=$ diamater paralon
$\mathrm{fw}=$ fokus wajan
$\mathrm{L} \quad=$ panjang pipa paralon yang diberi lakban alumunium
$\mathrm{S}=$ titik tempat penempatan modem USB 3G

Penghitungan nilai titik fokus wajan dilakukan dengan menggunakan persamaan:

$$
f w=\frac{D w^{2}}{16 d w}
$$

Sementara menghitung panjang pipa paralon yang diberi lakban alumunium (L) dan titik penempatan modem USB 3G (S) diperlukan langkah yang lebih panjang. Maka perhitungan harus dilakukan secara bertahap.

Dimana:

$$
\lambda=\frac{C}{\text { Freq }(\mathrm{Hz})}
$$

$\Lambda=$ panjang gelombang radio $1.950 \mathrm{MHz}$ di udara (satuan meter)

$\mathrm{C}=$ kecepatan cahaya di udara $\left(3 \times 10^{8}\right.$ meter/sekon)

Freq $=$ frekuensi operasi yang digunakan $1900 \mathrm{MHz}$ (satuan $\mathrm{Hz}$ )

Sehingga bila nilai-nilai tersebut dimasukkan ke dalam persamaanmenjadi:

$$
\begin{gathered}
\lambda=\frac{3 * 10^{8} \mathrm{~m} / \mathrm{s}}{1900 \mathrm{MHz}} \\
\lambda=15,385 \mathrm{~cm}
\end{gathered}
$$

Adapun diameter pipa paralon yang bisa digunakan harus memenuhi syarat:

$$
\begin{gathered}
0,6 \lambda<D<0,75 \lambda \\
9,231 \mathrm{~cm}<D<11,539 \mathrm{~cm}
\end{gathered}
$$

Dalam hal ini, pipa paralon 4” yang memiliki diameter $11 \mathrm{~cm}$ memenuhi syarat agar bisa digunakan sebagai waveguide.

Rumus untuk menghitung panjang guiding wavelength adalah:

$$
\lambda_{G}=\frac{\lambda}{\sqrt{1-\left(\frac{\lambda}{1,706 D}\right)^{2}}}
$$

Dimana:

$\lambda_{\mathrm{G}}=$ panjang guiding wavelength $($ dalam $\mathrm{cm})$

$\lambda=$ panjang gelombang radio $1950 \mathrm{MHz}$ di udara, bernilai15,385 cm

$\mathrm{D}$ = lebar diameter pipa paralon yang digunakan, dalam hal ini pipa paralon 4" mempunyai lebar $11 \mathrm{~cm}$

$$
\lambda_{G}=26,87 \mathrm{~cm}
$$

Adapun nilai panjang L minimal adalah:

$$
\begin{aligned}
& L_{\text {minimal }}=0,75 * \lambda_{G} \\
& L_{\text {minimal }}=20,15 \mathrm{~cm}
\end{aligned}
$$

Perlu diperhatikan bahwa panjang total pipa paralon yang digunakan adalah nilai $\mathrm{L}+\mathrm{fw}$. Untuk menentukan posisi lokasi lubang $\mathrm{S}$ dari ujung pipa paralon dapat digunakan persamaan:

$$
\begin{aligned}
& S=0,25 \lambda_{G} \\
& S=6,71 \mathrm{~cm}
\end{aligned}
$$


Tabel 1. Spektrum Frekuensi WCDMA

\begin{tabular}{|c|c|c|c|}
\hline Spektrum & Band Frekuensi & Operator & UL/DL \\
\hline & $1920-1925$ & PT. Hutchinson CP & UL \\
\hline & $1925-1930$ & PT NatrindoTS & UL \\
\hline & $1930-1935$ & PT NatrindoTS & UL \\
\hline & $1935-1940$ & PT. Telekomunikasi Selular & UL \\
\hline & $1940-1945$ & PT. Telekomunikasi Selular & UL \\
\hline & $1945-1950$ & PT. Hutchinson CP & UL \\
\hline & $1950-1955$ & PT. Indosat & UL \\
\hline & $1955-1960$ & PT. Indosat & $\mathrm{UL}$ \\
\hline & $1960-1965$ & PT. XL Axiata & UL \\
\hline & $1965-1970$ & PT. XL Axiata & $\mathrm{UL}$ \\
\hline & $1970-1975$ & \multicolumn{2}{|c|}{ Kosong/belum ada yang dialokasikan } \\
\hline & $1975-1980$ & \multicolumn{2}{|c|}{ Kosong/belum ada yang dialokasikan } \\
\hline & $2110-2115$ & PT. Hutchinson CP & $\mathrm{DL}$ \\
\hline & $2115-2120$ & PT NatrindoTS & DL \\
\hline & $2120-2125$ & PT NatrindoTS & DL \\
\hline & $2125-2130$ & PT. Telekomunikasi Selular & DL \\
\hline & $2130-2135$ & PT. Telekomunikasi Selular & DL \\
\hline & $2135-2140$ & PT. Hutchinson CP & $\mathrm{DL}$ \\
\hline & $2140-2145$ & PT. Indosat & $\mathrm{DL}$ \\
\hline & $2145-2150$ & PT. Indosat & DL \\
\hline & $2150-2155$ & PT. XL Axiata & DL \\
\hline & $2155-2160$ & PT. XL Axiata & DL \\
\hline & $2160-2165$ & $\begin{array}{c}\text { Kosong/belum ada yang } \\
\text { dialokasikan }\end{array}$ & \\
\hline & $2165-2170$ & Kosong/belum ada yang dia & kasikan \\
\hline
\end{tabular}




\section{Alat dan Bahan}

Alat-alat yang dibutuhkan dalam pembuatan antena wajanbolic adalah :

- Gergaji besi

- Penggaris

- Solder

- Cutter

- Pulpen atau sepidol untuk menandai yang akan dipotong

- Papan kayu untuk alas pengeboran

- Mesin Bor adalah :

Sedangkan bahan-bahan yang diperlukan

- Wajan alumunium dengan diameter $46 \mathrm{~cm}$

- Pipa paralon PVC Ø 4" sepanjang $40 \mathrm{~cm}$

- Tutup pipa paralon (Dop) PVC 4” sebanyak 2 buah

- Lakban alumunium 2 meter

- Pipa PVC 1,25” untuk dudukan Modem USB sepanjang $15 \mathrm{~cm}$

- Tutup pipa paralon (Dop) PVC 1,25” 1 buah

- Mur baut kecil untuk membaut dudukan Modem USB ke pipa paralon

- Mur baut agak besar untuk meng-klem salah satu tutup pipa paralon ke wajan

- Rubber tape

- Kabel USB Extension

- Modem USB 3G

\section{Pembuatan Antenna Wajanbolic}

Langkah 1, potong pipa pralon 4" sesuai dengan perhitungan yang telah dilakukan. Beri tanda pada lokasi batas lakban aluminium dan juga lokasi untuk membuat lubang untuk memasukan USB modem 3G. Lokasi lubang modem USB 3G berada pada jarak $6.8 \mathrm{~cm}$ dari belakang pipa pralon. Bor lubang untuk USB modem dan kerik menggunakan cutter agar USB dapat masuk ke lubang yang tersedia.

Langkah 2. Siapkan dop pralon 4” yang akan ditutupkan ke pipa pralon. Beri lakban aluminium pada dop pralon. Pastikan ada sedikit lakban aluminium di pinggir-nya supaya aluminium-nya nanti bersentuhan dengan aluminium yang ada pada badan pipa pralon.

Langkah 3. Beri lakban aluminium pada badan pipa pralon sampai $25 \mathrm{~cm}$ dari ujung. Lubangi menggunakan cutter lokasi tempat masuknya USB modem pada jarak $6.8 \mathrm{~cm}$ dari ujung. Tutupkan dop pralon 4" yang kita beri lakban pada pipa pralon.

Langkah 4. Lubangi penggorengan dan dop pralon yang ke dua di tengah-nya. Pasang dop pralon ke wajan menggunakan mur dan baut.

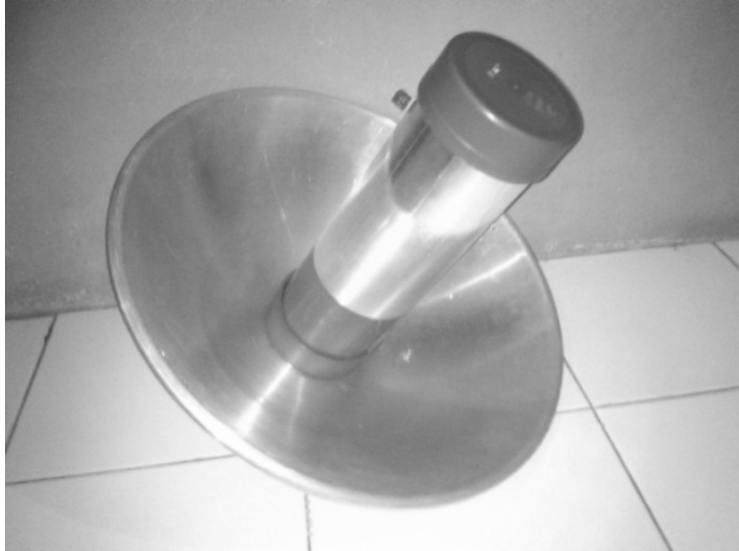

Gambar 9. Antena wajanbolic yang telah jadi

\section{Pembuatan Kabel USB Extender}

Pada kenyatannya, aplikasi antenna wajanbolic membutuhkan kabel yang panjang untuk tersambung ke PC atau laptop.Karena antena wajanbolic membutuhkan koneksi line of sight, maka tidak jarang harus memasang antena wajanbolic pada ketinggaian tertentu untuk memperoleh line of sight agar tidak terhalang oleh apapun. Jika menggunakan kabel USB biasa jelas tidak akan mungkin karena pada umumnya kebel USB biasa pendek, dan jika dipaksakan disambung sampai panjang maka data akan loss di tengah jalan. Jika menggunakan kabel USB active extender maka harga akan menjadi mahal. Sehingga digunakan kabel USB extender yang dibuat dari kabel UTP yang ujungnya dikonversi ke USB. Berikut akan diuraikan cara pembuatan kabel USB ekstender. Alat yang diperlukan adalah Cutter dan Solder. Sedangkan bahan yang diperlukan adalah :

- Kabel UTP \pm 10 meter

- Kabel USB extender +1 meter

- Timah untuk menyolder

- Selotip

- Pipa kecil $\pm 5 \mathrm{~cm} \times 2$ buah

- Lakban

Cara pembuatannya adalah sebagai berikut :

- Siapkan semua alat dan bahan yang diperlukan

- Kupas selongsong luar dari kabel UTP di kedua ujung

- $\quad$ Potong kabel USB jadi 2

- Kupas juga selongsong luar dari kabel USB

- Kupas ujung kabel UTP dan USB $\pm 3 \mathrm{~mm}$ untuk sambungan

- Pasang potongan pipa kecil untuk melindungi kabel sebelum disolder

- Solder kabel UTP ke kabel USB dengan cara sebagai berikut:

o Kabel UTP orange - putih orange disatukan untuk menghubungkan pin $+5 \mathrm{~V}$ (kabel USB merah)

o Kabel UTP putih hijau dihubungkan dengan pin Data+ (kabel USB putih)

o Kabel UTP hijau dihubungkan dengan 
Data- (kabel USB hijau)

o Kabel UTP putih biru, biru, putih coklat, coklat disatukan untuk menghubungkan ke Ground (kabel USB hitam)

- Setelah semua kabel tesambung dengan baik, lapisi sambungan kabel dengan selotip agar tidak terjadi hubungan pendek

- Rekatkan pipa paralon denga lakban untukmelindungi sambungan

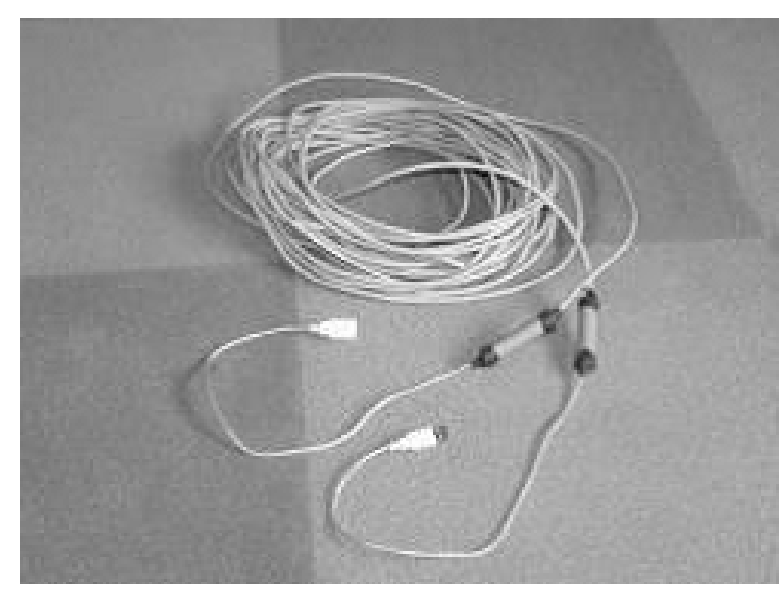

Gambar 9. Hasil akhir pembuatan kabel USB extender

\section{PENGUKURAN DAN ANALISIS \\ Umum}

Pengukuran berapa penguatan sinyal yang diperoleh sebelum dan setelah menggunakan antenna wajanbolic dapat diukur dengan bantuan software, antara lain MDMA, QPST, dan QXDM.

Dalam pengujian ini tidak dapat dilakukan pengukuran pola radiasi karena selalu terdapat lebih dari 1 base station ketika pengujian.

Beberapa hal yang perlu diperhatikan sebelum pengukuran adalah, menghindari gangguan pantulan (benda-benda disekitar tempat pengukuran) berdasarkan fresnel zone, jarak antara pemancar dan penerima, serta arah dari base station yang akan kita tuju.

\section{Persiapan} ini adalah :

Peralatan yang digunakan dalam pengukuran

- Antena wajanbolic

- Modem USB 3G

- USB extension

- Laptop (yang telah terinstal program MDMA, QPST, dan QXDM)

\section{Pengukuran Gain}

Untuk pengukuran gain maksimum antena wajanbolic ini dilakukan dengan cara membandingkan level sinyal maksimum yang diterima modem USB 3G dengan level sinyal maksimum yang diperoleh antena wajanbolic.
Langkah-langkah untuk mengetahui nilai level sinyal yang diperoleh oleh modem USB 3G adalah sebagai berikut:

- Nyalakan laptop.

- Hubungkan modem USB 3G ke laptop.

- Jalankan program MDMA, setelah itu QXDM.

- Amati level sinyal yang diperoleh.

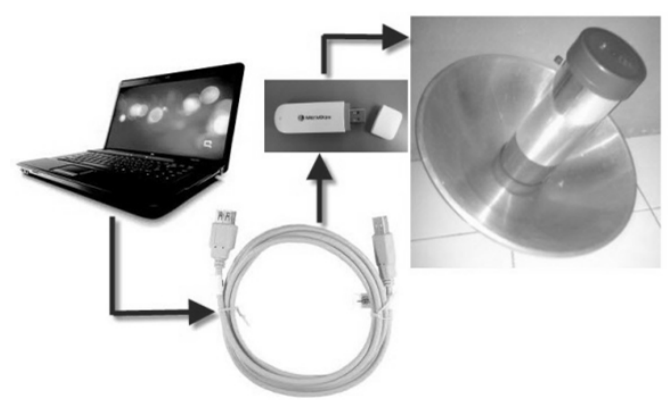

Gambar 10. Diagram pengukuran level sinyal

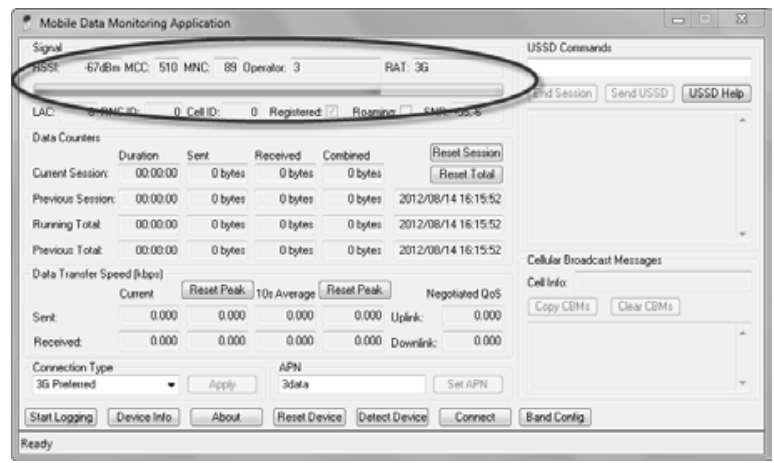

Gambar 11. Hasil pengukuran tanpa antenna wajanbolic dengan MDMA

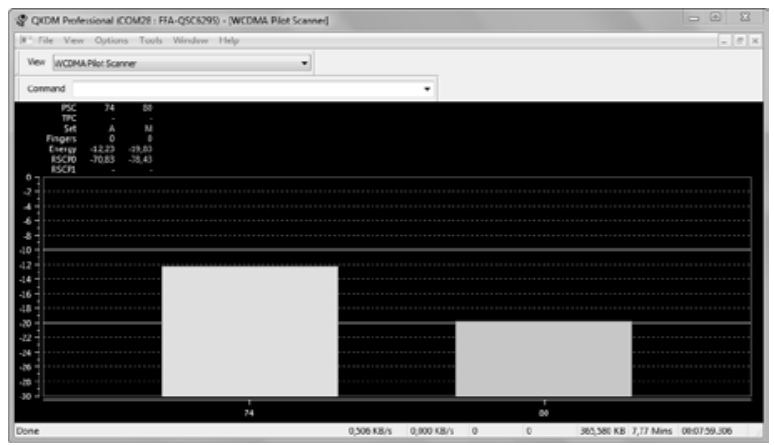

Gambar 12. Hasil Scanning Sinyal Pada QXDM

Selanjutnya amati level sinyal ketika menggunakan antenna wajanbolic yang diarahkan LoS ke base station: 


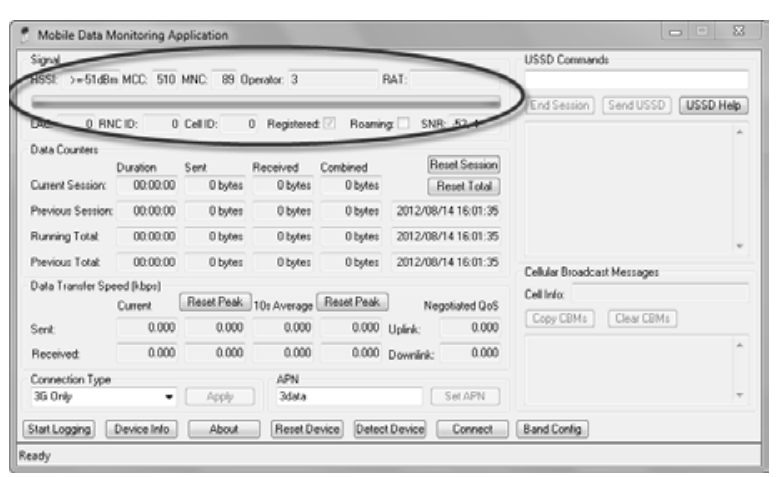

Gambar 13. Hasil penguatan yang ditunjukkan program MDMA

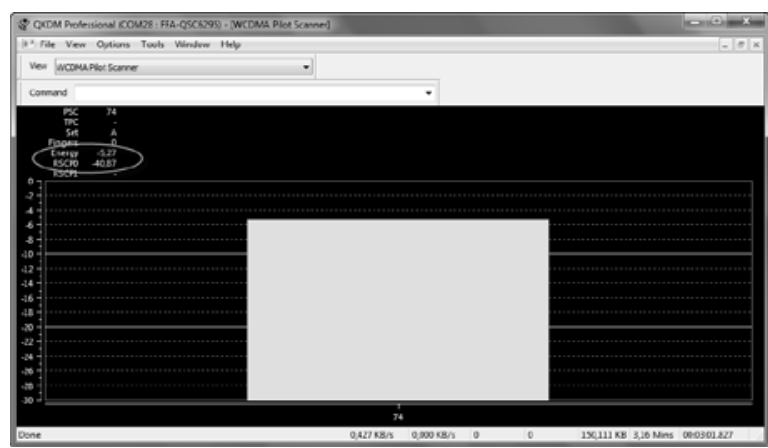

Gambar 13. Hasil penguatan yang ditunjukkan pogram QXDM

Pada pengukuran antenna wajanbolic didapatkan kekuatan sinyal yang dapat dibaca dari program MDMA adalah >=-51dBm. Sementara pada program QXDM hanya terdeteksi 1 sinyal BTS, hal ini menunjukkan antenna bekerja dengan baik karena pola radiasinya terarah karena sinyal dari BTS 74 menguat ke $-40,87 \mathrm{dBm}$ dan BTS yang lainnya melemah.

$$
\begin{gathered}
P[d B m]=G[d B]+K \\
-67 d B m=G+(-51 d b m) \\
G=16 d B
\end{gathered}
$$

\section{Pengkuran Transfer Data}

Pengujian ini dilakukan dalam waktu yang hampir bersamaan (dengan dan tanpa antenna wajanbolic serta dalam tempat yang sama). Berikut adalah hasil perbandingan kecepatannya:

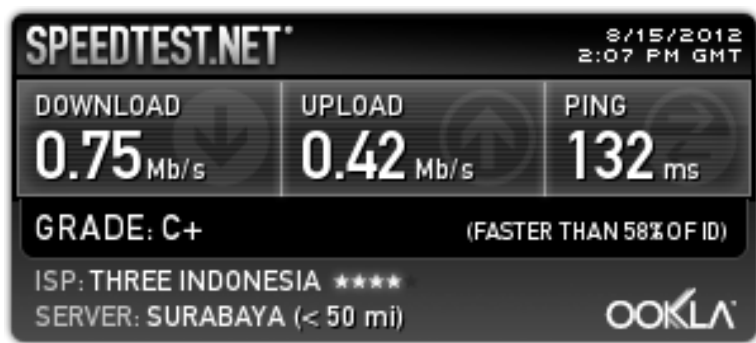

Gambar 14. Pengukuran tanpa antenna

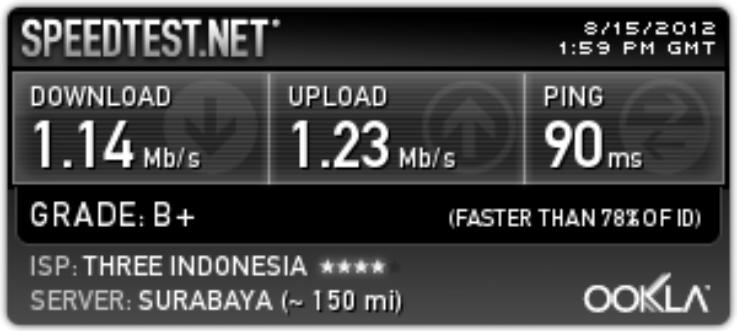

Gambar 15 Pengukuran dengan antenna

\section{PENUTUP}

Kesimpulan

Berdasarkan hasil pengukuran dan analisa, maka dapat disimpulkan bahwa:

- Antena wajanbolic adalah antena directional yang mempunyai keterarahan sinyal. Dalam aplikasi penggunaannya antenna wajanbolic harus dalam kondisi Line of Sight (LoS) antara antenna pemancar (Base Station) dan antenna penerima.

- Antena wajanbolic 46 centimeter ini mempunyai nilai gain sebesar $\pm 16 \mathrm{~dB}$ pada jarak 2-3 km antara antenna pemancar (Base Station) dan antenna penerima.

- Pada Tugas Akhir ini, antena wajanbolic yang telah dibuat telah berhasil sesuai performansi yang diharapkan. Hal ini dapat dilihat dari, gain, dan kecepatan transfer datayang dimiliki oleh antena wajanbolic yang telah dibuat.

Saran

Untuk pengembangan lebih lanjut dari antenna wajanbolic bisa dilakukan hal-hal sebagai berikut antara lain:

- Perbaikan dalam perancangan konstruksi, untuk mendapatkan titik focus yang optimal bisa dilakukan dengan merancang sendiri reflector yang akan digunakan. Sehingga akan didapatkan Gain yang lebih tinggi.

- Karena antenna membutuhkan keadaan LoS terhadap pemancar, kemungkinan besar akan diletakkan di ruang terbuka, oleh karena itu penambahan penangkal petir (antenna arrester) bisa menjadi solusi untuk proteksi antenna wajanbolic ini.

- Penggunaan modem USB 3G dengan merek yang lebih baik untuk mendapatkan performansi yang lebih optimal.

\section{DAFTAR PUSTAKA}

1. Alaydrus, Mudrik. , 2011, Antena (Prinsip \& Aplikasi). Yogyakarta: Graha Ilmu.

2. Purbo, Onno W., 2006, Internet Wireless dan HotSpot. Jakarta: P.T. Elex Media Komputindo.

3. Santoso, Gatot., 2004, Sistem Selular WCDMA. Yogyakarta: Graha Ilmu. 
4. Zennaro, Marco dan Carlo Fonda, 2004, Radio Laboratory Handbook Vol. 1 Cables and Antennas.

5. Tutorial Lengkap Cara Menggunakan Software QXDM dan QPST http://teknikit.com/2012/02/tutorial-lengkapcara-menggunakan-software-qxdm-danqpst.html. (15 Agustus 2012, jam 20:48)

6. Wajanbolic e-goen http://opensource.telkomspeedy.com/wiki/inde x.php/Wajanbolic_e-goen. (2 Juni 2012, jam 19:37)

7. Kepemilikan dan masa berlaku Spektrum frekuensi UMTS (WCDMA)

http://statistik.kominfo.go.id/site/data?idtree=2 45\&iddoc=709. (18 September 2012, jam 10:43) 